\section{Systematic reviews of interventions for preventing sleep-related injuries}

\section{SLEEPINESS AS A RISK FACTOR FOR INJURY}

Sleepiness is an important risk factor for injury. Insufficient sleep leads to a deterioration of performance, attention, motivation, mental concentration and intellectual capacity, ${ }^{1}$ which leads to an increased risk of error and injury. The potential consequences of such errors vary enormously; many will be inconsequential and easily compensated for without any adverse effects, whereas others can have devastating effects.

A consensus statement endorsed by an international group of sleep experts states that "fatigue (sleepiness, tiredness) is the largest identifiable and preventable cause of accidents in transport operations (between $15 \%$ and $20 \%$ of all accidents), surpassing that of alcohol or drug related incidents in all modes of transportation". ${ }^{2}$ One survey in England found that sleep-related incidents comprised $16-20 \%$ of all police-attended motor vehicle crashes. ${ }^{3}$ Occupational injuries are also associated with sleepiness, with observational studies having found that workers with higher levels of sleepiness have a greater risk of experiencing an occupational injury than those with the lower levels of sleepiness. ${ }^{4} 5$

A further area of concern is the sleepiness of healthcare providers, which has been identified as an important cause of medical errors. ${ }^{6-8}$ There is evidence for a relationship between medical errors and insufficient sleep: a meta-analysis found that sleep deprivation of 24-30 h reduced clinical performance by 1.5 standard deviations, ${ }^{9}$ and shifts of $\geqslant 24 \mathrm{~h}$ duration have been found to be associated with increased risk of medical errors. ${ }^{10}$ Medical errors have also been shown to occur more frequently during night shifts. ${ }^{11-13}$

\section{CAUSES OF SLEEPINESS}

The main causes of sleepiness and the associated impairment in alertness experienced by healthy individuals are inadequate nocturnal sleep and patterns of activity that do not conform to the circadian sleep-wake cycle (eg, night work). ${ }^{14}$ However, people can experience sleepiness despite having obtained adequate sleep-mental fatigue can occur after or during prolonged periods of demanding cognitive activity which requires sustained mental efficiency, ${ }^{15}$ and there are time-ofday fluctuations in our alertness, which are dictated by our circadian rhythm and occur independently of sleep history. ${ }^{16}$

\section{INJURY PREVENTION INTERVENTIONS}

There is no substitute for the restorative effects of sleep; obtaining an adequate amount of good-quality, natural sleep is by far the most effective and safe measure for preventing the detrimental effects of lack of sleep, including injury and error. However, we live in an increasingly 24-hour society, with a need and demand for services outside the conventional nine-to-five working hours. The identification of effective and safe interventions is essential to ensure that those who need to operate while experiencing sleepiness can do so safely without putting their health, or indeed the health of others, at risk. The Cochrane Injuries Group (CIG) is therefore preparing systematic reviews of the evidence in this area.

\section{CIG'S SYSTEMATIC REVIEWS IN PROGRESS}

The reviews currently underway are including randomised trials assessing the effects of interventions for preventing the occurrence of injury or error associated with sleepiness. Separate reviews are being prepared for studies focusing on people who are sleep deprived, those working shifts or experiencing jet-lag, and those who are not sleep deprived. A broad range of interventions are eligible in the reviews ranging from pharmacological stimulants (to promote wakefulness), pharmacological sedatives (to encourage daytime sleep), non-pharmacological interventions (including shift patterns, bright light, rest breaks) and error-prevention systems (such as alarms). The outcomes of interest are the occurrence of injuries and error, as well as cognitive performance.

To the best of our knowledge these will be the first systematic reviews aimed at assessing the effects of any intervention designed to prevent injuries caused by sleepiness, and we hope that they will serve as resources for all sectors that seek to address the burden of such harm.

The protocols for these reviews are published in the Cochrane Database of Systematic Reviews, ${ }^{17-19}$ and work is under way on the reviews. These reviews are funded through the NHS Cochrane Collaboration Programme Grant Scheme, National Institute for Health Research, UK.

For more information about the work of the CIG, please visit the website at http://injuries.cochrane.org/en/index.html. All CIG's protocols and reviews are published in the Cochrane Database of Systematic Reviews accessed at www.thecochranelibrary.com.

Competing interests: None.

Provenance and peer review: Commissioned; not externally peer reviewed.

Injury Prevention 2009;15:428. doi:10.1136/ip.2009.024984

\section{REFERENCES}

1. WHO. WHO technical meeting on sleep and health. Bonn: World Health Organization Regional Office for Europe, 2004.

2. Akerstedt T. Consensus statement: fatigue and accidents in transport operations. J Sleep Res 2000;9:395.

3. Horne JA, Reyner LA. Sleep related vehicle accidents. BMJ 1995;310:565-7.

4. Melamed S, Oksenberg A. Excessive daytime sleepiness and risk of occupational injuries in non-shift daytime workers. Sleep 2002;25:315-22.

5. Swaen GM, Van Amelsvoort LG, Bultmann U, et al. Fatigue as a risk factor for being injured in an occupational accident: results from the Maastricht Cohort Study. Occup Environ Med 2003;60(Suppl 1):i88-92.

6. Gaba DM, Howard SK. Patient safety: fatigue among clinicians and the safety of patients. N Engl J Med 2002;347:1249-55.

7. Jha AK, Duncan BW, Bates DW. Fatigue, sleepiness, and medical errors. In Making health care safer. A critical analysis of patient safety practices. Chapter 46. Evidence Report/Technology Assessment, No 43 edn, 2001. http://www.ahrq.gov/Clinic/ ptsafety/chap46a.htm (accessed 18 Sep 2009).

8. Kohn L, Corrigan J, Donaldson M, eds. To err is human. Building a safer health system. Institute of Medicine report. Washington, DC: National Academy Press, 1999.

9. Philibert I. Sleep loss and performance in residents and nonphysicians: a metaanalytic examination. Sleep 2005;28:1392-402.

10. Barger L, Ayas N, Cade B, et al. Impact of extended-duration shifts on medical errors, adverse events, and attentional failures. PLOS Med 2006;3:2440-8.

11. Eastridge BJ, Hamilton EC, O'Keefe GE, et al. Effect of sleep deprivation on the performance of simulated laparoscopic surgical skill. Am J Surg 2003;186:169-74.

12. Ayas NT, Barger LK, Cade BE, et al. Extended work duration and the risk of selfreported percutaneous injuries in interns. JAMA 2006;296:1055-62.

13. Grantcharov TP, Bardram L, Funch-Jensen P, et al. Laparoscopic performance after one night on call in a surgical department: prospective study. BMJ 2001;323:1222-3.

14. Breslau N, Roth T, Rosenthal L, et al. Daytime sleepiness: an epidemiological study of young adults. Am J Public Health 1997;87:1649-53.

15. Lorist MM, Boksem MA, Ridderinkhof KR. Impaired cognitive control and reduced cingulate activity during mental fatigue. Brain Res Cogn Brain Res 2005;24:199-205.

16. Wesensten NJ, Balkin TJ, Belenky G. The role of sleep in sustaining individual and organizational effectiveness. In: Barko WF, Vaitkus MA, eds. The US Army War College guide to executive health and fitness, 2000. http://www.cdc.gov/hccdphp/ dnpa/usphs/pdfs/army.pdf (accessed 18 Sep 2009).

17. Ker K, Edwards P, Roberts I, et al. Interventions for preventing injuries caused by impaired alertness in individuals with jet lag and shift work disorder (Protocol). Cochrane Database Syst Rev 2009;(2):CD007741.

18. Ker K, Edwards P, Roberts I, et al. Interventions for preventing injuries caused by impaired alertness in individuals who are sleep deprived (Protocol). Cochrane Database Syst Rev 2009;(2):CD007740.

19. Ker K, Edwards P, Roberts I, et al. Interventions for preventing injuries caused by impaired alertness in individuals who are not sleep deprived (Protocol). Cochrane Database Syst Rev 2009;(2):CD007739. 